Pacific Journal of Mathematics

A CHARACTERIZATION OF THE REPRESENTABLE
LEBESGUE DECOMPOSITION PROJECTIONS 


\title{
A CHARACTERIZATION OF THE REPRESENTABLE LEBESGUE DECOMPOSITION PROJECTIONS
}

\author{
Wayne C. Bell and Michael Keisler
}

\begin{abstract}
Finitely additive measures whose Lebesgue decomposition projections have refinement integral representations are characterized in terms of certain atomic properties.
\end{abstract}

In [2] it was shown that under certain fairly weak conditions the dual of $b a(S, F)$ does not have a refinement integral representation since these conditions lead to a $\mu \in b a(S, F)$ for which $T_{\mu}$, the linear functional associated with the Lebesgue decomposition projection $P_{\mu}$, is not representable. In [1] it was shown that for any $\mu>0$ there is a maximal "nonrepresentable" part. Here we combine these results to give a necessary and sufficient condition under which $T_{\mu}$ is representable.

A nonnegative $\mu$ in $b a(S, F)$ is atomic if $I \in F$ such that $\mu(I)>$ 0 implies $I$ contains a $\mu$-atom $J$ (i.e., $J \in F, \mu(J)>0$ and for $K \in$ $F$ and $K \subseteq J, \mu(K) \in\{0, \mu(J)\}$. In this paper we are interested in a stronger notion of atomic.

Definition. If $\mu \in b a(S, F)$ and $\mu \geqq 0$, then $\mu$ is totally atomic if each $\lambda \in b a(S, F)$ such that $0 \leqq \lambda \leqq \mu$ is atomic.

A totally atomic $\mu$ is a sum of two-valued measures, but the converse statement is false. It was noted in [3] that for the $\sigma$-field $P(N)$ one may select a $\mu^{\prime} \geqq 0$ which is a sum of two-valued measures and for which there are no $\mu^{\prime}$-atoms in $P(N)$. Letting $\lambda \geqq 0$ be a sum of $\lambda_{n}$, where $\lambda_{n}$ is two-valued and $\{n\}$ is a $\lambda_{n}$-atom, for every $n$, we then have that $\mu^{\prime}+\lambda$ is a sum of two-valued measures which is also atomic but still not totally atomic.

It may be noted that $T_{\mu}(\lambda)=P_{\mu}(\lambda)(S)$, for $\lambda \in b a(S, F)$, defines a member of the dual of $b a(S, F)$. If $\eta \in b a(S, F)$, and $f: F \rightarrow R$, then $T_{\mu}(\lambda)=\int_{s} f \lambda$, for $\lambda \in b a(S, F)$ (“ $T_{\mu}$ is representable") iff $P_{\mu}(\lambda)=$ $\int f \lambda$, for $\lambda \in b a(S, F)(" \mu$ is representable" in [1]). The equivalence is an immediate consequence of the definition of $T_{\mu}$, and is useful below.

TheoRem. Let $\mu \in b a(S, F)$ and $\mu \geqq 0$. The following are equivalent.

(i) $T_{\mu}$ is representable.

(ii) $\mu$ is totally atomic. 
Proof. In Theorem 2 of [1] it was shown that $\mu=\lambda+\eta$, where $\lambda$ is representable and if $I \in F$, then $\eta^{I}$ is representable iff $\eta^{I}=$ $0\left(\eta^{I}(V)=\eta(I \cap V)\right.$ for $\left.I, V \in F\right)$. If $I$ is an $\eta$-atom, then clearly $\eta^{I}$ is representable. Thus $\eta$ has no atoms. If $\mu$ is totally atomic, then $\eta=0$. Therefore $\mu=\lambda$ and we have that $\mu$ is representable.

If $\mu$ is not totally atomic, then there is $\lambda \in b a(S, F)$ such that $0 \leqq \lambda \leqq \mu$ and $I \in F$ such that $\lambda(I)>0$ and $I$ contains no $\lambda$-atom. Thus if $J \in F$ and $\lambda^{I}(J)>0$, then there is $K \in F$ for which $K \subseteq J$ and $\lambda^{I}(K) \notin\left\{0, \lambda^{I}(J)\right\}$. By Theorem 2 of [2], $\lambda^{I}$ is not representable, and by 3.c.1. of [1] it follows that $\mu$ is not representable.

\section{REFERENCES}

1. Wayne C. Bell, A decomposition of additive set functions, Pacific J. Math., 72 (1977), 305-311.

2. Michael Keisler, Integral representations for elements of the dual of $b a(S, \Sigma)$, Pacific J. Math., 83 (1979), 177-183.

3. Dorothy Maharam, Finitely additive measures on the integers, Sankhyā, series A, 38 (1976), 44-59.

Received July 19, 1978.

MURRAY STATE UNIVERSITY

MURRAY, KY 42071

AND

Arkansas TeCh UnIversity

RUSSELLVILLE, AR 


\section{PACIFIC JOURNAL OF MATHEMATICS}

EDITORS

DONALD BABBITT (Managing Editor)

University of California

Los Angeles, California 90024

Hugo RossI

University of Utah

Salt Lake City, UT 84112

C. C. MOORE and ANDREW OGG

University of California

Berkeley, CA 94720

\section{J. DUGUNDJI}

Department of Mathematics University of Southern California Los Angeles, California 90007

R. Finn and J. Milgram Stanford University

Stanford, California 94305

\section{ASSOCIATE EDITORS}
E. F. BECKENBACH
B. H. Neumann
F. WOLF
K. YoSHIDA

\section{SUPPORTING INSTITUTIONS}

UNIVERSITY OF BRITISH COLUMBIA

CALIFORNIA INSTITUTE OF TECHNOLOGY

UNIVERSITY OF CALIFORNIA

MONTANA STATE UNIVERSITY

UNIVERSITY OF NEVADA, RENO

NEW MEXICO STATE UNIVERSITY

OREGON STATE UNIVERSITY

UNIVERSITY OF OREGON
UNIVERSITY OF SOUTHERN CALIFORNIA

STANFORD UNIVERSITY

UNIVERSITY OF HAWAII

UNIVERSITY OF TOKYO

UNIVERSITY OF UTAH

WASHINGTON STATE UNIVERSITY

UNIVERSITY OF WASHINGTON 


\section{Pacific Journal of Mathematics}

\section{Vol. 83, No. 1 \\ March, 1979}

Richard Neal Ball, Topological lattice-ordered groups ............... 1

Stephen Berman, On the low-dimensional cohomology of some

infinite-dimensional simple Lie algebras .................. 27

R. P. Boas and Gerald Thomas Cargo, Level sets of derivatives ......... 37

James K. Deveney and John Nelson Mordeson, Splitting and modularly

perfect fields......................................

Robert Hugh Gilman and Ronald Mark Solomon, Finite groups with small

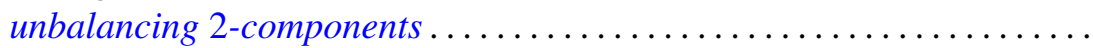

George Grätzer, Andras Hajnal and David C. Kelly, Chain conditions in free products of lattices with infinitary operations..................

Benjamin Rigler Halpern, Periodic points on tori ..................

Dean G. Hoffman and David Anthony Klarner, Sets of integers closed under

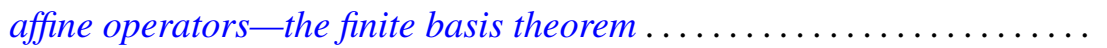

Rudolf-Eberhard Hoffmann, On the sobrification remainder ${ }^{s} X-X \ldots \ldots$

Gerald William Johnson and David Lee Skoug, Scale-invariant

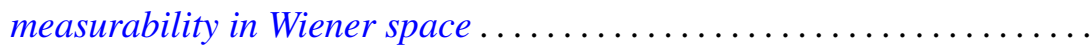

Michael Keisler, Integral representation for elements of the dual of

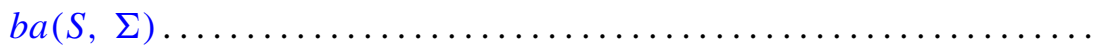

Wayne C. Bell and Michael Keisler, A characterization of the representable Lebesgue decomposition projections ................

Wadi Mahfoud, Comparison theorems for delay differential equations ...

R. Daniel Mauldin, The set of continuous nowhere differentiable functions .

Robert Wilmer Miller and Mark Lawrence Teply, The descending chain condition relative to a torsion theory...

Yoshiomi Nakagami and Colin Eric Sutherland, Takesaki's duality for regular extensions of von Neumann algebras ........ .

William Otis Nowell, Tubular neighborhoods of Hilbert cube manifolds ...

Mohan S. Putcha, Generalization of Lentin's theory of principal solutions of word equations in free semigroups to free product of copies of positive reals under addition

Amitai Regev, A primeness property for central polynomials . ...

Saburou Saitoh, The Rudin kernels on an arbitrary domain. . .

Heinrich Steinlein, Some abstract generalizations of the

Ljusternik-Schnirelmann-Borsuk covering theorem . . . 